\title{
Antimicrobial Activity of Azadirachta indica, against Target Pathogens and Its Utility as a Disinfectant and Floor Cleaner
}

\author{
Mohsin Ali Khan ${ }^{1}$, Shadma Yaqoob², Sharique Ahmad ${ }^{3}$ \\ ${ }^{1}$ Department of Medical Research, Era's Lucknow Medical College and Hospital, Era University, \\ Lucknow, Uttar Pradesh, India, ${ }^{2}$ Department of Microbiology, Era's Lucknow Medical College \\ and Hospital, Era University, Lucknow, Uttar Pradesh, India, ${ }^{3}$ Department of Pathology, Era's \\ Lucknow Medical College and Hospital, Era University, Lucknow, Uttar Pradesh, India.
}

\section{ABSTRACT}

\section{BACKGROUND}

Azadirachta indica, commonly known as neem, neem tree or Indian lilac, Limbo, Nim, Nimba, Medusa and Vempu. It is typically grown in tropical and subtropical regions. Neem belongs to family meliaceae. Neem is a native tree of India. It is also called "village pharmacy of south Asia" (India) because of its enormous medicinal properties and people use it most of the time without knowing its multiple advantages. This study was done to know the efficacy of medicinal plant named Azadirachta indica (Neem) against pathogenic microorganisms and about its utility as disinfectant and floor cleaner.

\section{METHODS}

Agar well diffusion method, Culture plate method, inoculum preparation \& its subculture methods were used to determine the antimicrobial activity of the neem leaf extract. Different concentrations of neem leaf extracts in culture plates were used for the study. In this method inhibited zones were measured.

\section{RESULTS}

Neem leaf extracts showed considerable antimicrobial activity against four target pathogens. In agar well diffusion method it showed maximum antimicrobial activity against Enterococcus and Staphylococcus aureus. Growth of inhibition was increased as the concentration of the neem extract in agar media increased and was maximum for Staphylococcus aureus.

\section{CONCLUSIONS}

The extract of $A$. indica, has antimicrobial activity against target pathogens Enterococcus, Staphylococcus aureus, Pseudomonas, and E.coli. With the old medicinal knowledge on neem, better economic and therapeutic utilization can be done by using modern approaches of drug development.

\section{KEY WORDS}

Neem Leaf extract, Antimicrobial Activity, Agar Well Diffusion Test, Zone of Inhibition
Corresponding Author:

Dr. Shadma Yaqoob, Department of Microbiology,

Era's Lucknow Medical College and Hospital, Era University, Lucknow 226003, Uttar Pradesh, India.

E-mail: drshadmayaqoob@yahoo.com

DOI: $10.14260 /$ jemds/2021/392

How to Cite This Article:

Khan MA, Yaqoob $S$, Ahmad $S$. Antimicrobial activity of azadirachta indica, against target pathogens and its utility as a disinfectant and floor cleaner. $J$ Evolution Med Dent Sci 2021;10(25):18991903, DOI: 10.14260/jemds/2021/392

Submission 01-02-2021,

Peer Review 23-04-2021,

Acceptance 30-04-2021,

Published 21-06-2021.

Copyright (C) 2021 Mohsin Ali Khan et al. This is an open access article distributed under Creative Commons Attribution License [Attribution 4.0 International (CC BY 4.0)] 


\section{BACKGROUND}

Azadirachta indica also known as "Indian neem / Margosa tree", is one of the oldest and important medicinal plants in India and other countries having different types of biological activity. ${ }^{1}$

Neem having wide range of medicinal properties has attracted the World. Different parts of neem tree like leaves, stems, flowers, roots and bark, all have different and valuable uses. In olden times it was used as household remedy against various human ailments. $2,3,4$ In ancient times the neem tree was extensively in use for the treatment of various types of diseases as quoted in numerous Ayurveda compositions but slowly with modernization of the therapeutic pharmacology and its branches the Ayurveda took a back seat and significance of it reduced but as of now the modern medical science is again exploring the ethnic and organic drugs for the better therapeutic management due to side effects of chemical based pharmacological compositions in use, so, presently a lot of research in going on in naturotherapy, nutraceuticals and compositions related to it. Few studies are coming up with promising findings for the various diseases and of all these studies 'neem' tree is one of the exclusive plants which is extensively researched.

Its products are mostly used in Ayurveda and Unani medicines because of its antibacterial, antiviral, antifungal properties and is also used to treat skin diseases ${ }^{5}$ (a paste of neem leaves and turmeric can be used for treating insect bites, itching ), inflammation, infections and dental disorders.6,7,8 As noted earlier, both in India and Africa millions of people use twigs of neem as "toothbrushes" every day. Dentists have researched about this ancient practice, finding it effective in preventing periodontal disease. ${ }^{8}$ Neem leaf has maximum medicinal value and a wide range of pharmacological activities. ${ }^{9}$ Chewing neem leaves can be beneficial for hair too, with its high levels of antioxidants. Washing hair with boiled neem water has been a traditional method. Neem is considered as antimicrobial plant because of various activities like it can destroy microbial growth by penetrating to the infected site, thus preventing the initiation of drug resistance. ${ }^{10,11}$

Because of its penetrating property it can be used for preparing floor cleaners. It is free from toxins and poisons that are hazardous to human health compared to other commercial floor cleaners available today. These chemical floor cleaners may also contribute to their stronger resistance. But some natural sources such as neem, aloe vera, eucalyptus oil etc. are nontoxic, non-synthetic, having antibacterial properties and can be used as ingredients in floor cleaners.12,13

It can cure many more ailments but is not claimed because it has not been independently confirmed by trials under controlled conditions. Neither indications nor trial was present to prove that neem may be used in future much more widely. These promising, but unproved, applications include anti-inflammatory, hypotensive, and anti-ulcer treatments.

Neem is also used in the treatment of peptic ulcer. Aqueous neem leaves extract also contain antiulcer activity and very significant effect on Wistar rats at the dose of $600 \mathrm{mg} / \mathrm{kg}$. The anti-ulcer mechanism of aqueous neem leaf extract to block gastric lesions in rats which has been studied with oxidative damage, apoptosis and acid secretion. It is due to inhibition of $\mathrm{H}+\mathrm{K}+$ ATPase activity.

\section{METHODS}

The study was done after approval from institutional ethical committee in the Department of Microbiology and Pathology, Era's Lucknow Medical College and Hospital, Lucknow for a period of 6 months from December 2019 to December 2020. Study was intramural inter-departmental observational type.

Specimens and instruments required were

- Neem leaf extract

- Gram positive and Gram-negative bacterial cultures of Enterococcus, Staphylococcus aureus, Pseudomonas and E.coli.

- Blood agar and MacConkey agar culture plate

- Brain heart infusion broth, normal saline, Borer

\section{Part 1 - Preparation of Neem Leaf Extracts}

Neem leaves taken freshly from Nursery of Era's Lucknow Medical College \& Hospital, were washed in sterilized, distilled water and weighed 25 gms. $50 \mathrm{ml}$ of absolute ethanol was mixed with 25 gms of fresh neem leaves and the mixture was kept for 2 minutes, then filtered with muslin fabric to remove coarse residue. Coarse residue left was mixed again with $25 \mathrm{ml}$ ethanol for further extraction. Both the extracts were mixed and filtered for clean extraction. Removed ethanol part from the extract was kept on water bath till the volume became 25 ml. Extract was stored in airtight container.

\section{Preparation of Inoculum}

2 to 3 colonies of pure growths were taken and emulsified in sterile brain heart infusion (BHI) broth. The bacterial culture (inoculum) was prepared and adjusted according to the turbidity of a McFarland 0.5 scale. This inoculum was kept for 30 minutes.

Preparation of Neem Extract Blood Agar and MacConkey Agar Plates

- $2 \mathrm{ml}, 4 \mathrm{ml}$ and $6 \mathrm{ml}$ neem extracts were added in melted Blood agar for Gram positive and MacConkey agar for Gram negative bacteria.

- Petri dishes were left undisturbed until the medium was set.

\section{Part II (Procedure) \\ Method I}

Agar well diffusion method was used for testing of antibacterial activity of the neem. Cultured the inoculum on the agar plates. After some time, at the centre of the agar culture plates, $6 \mathrm{~mm}$ diameter circles were visible. A control normal saliva was used. After the period of incubation, agar culture plates were removed, and zone of inhibition was recorded.

\section{Method II}

After 30 minutes, inoculum was inoculated on two sets of culture plates i.e., without and with neem leaves extract as prepared above and kept in an incubator at $37^{\circ} \mathrm{C}$ for 24 hours.

\section{Method III}

Six test tubes were taken. $3 \mathrm{ml}$ of neem extract was put in five test tubes \& one with normal saline. $1 \mathrm{ml}$ of inoculum prepared by four different bacteria added to each of the four test tubes 
of neem extract. No inoculum was added in fifth test tube of neem extract and other with saline that were kept as control. Tubes were left undisturbed for 2 hrs. After $2 \mathrm{hrs}$, turbidity was recorded and suspensions prepared were cultured on Blood agar and MacConkey agar with the help of wire loop. These culture plates were incubated for 24 hours at $37^{\circ} \mathrm{C}$.

\section{Statistical Analysis}

We noted all the findings and observational analysis and corroborated with culture reports. Data were entered into a Microsoft excel spreadsheet and then analysed by SPSS (version 24.0; SPSS Inc., Chicago, IL, USA, and GraphPad Prism version 5). Paired $\mathrm{T}$ - tests were a form of blocking and had greater power than unpaired tests. Unpaired proportions were compared by chi-square test or Fischer's exact test, as appropriate. Correlation was calculated by Pearson correlation analysis. The P - value was considered as statistically significant when it was less than 0.05

\section{RESULTS}

We tested medicinal plant $A$. Indica (Neem), for its antimicrobial activity against target pathogens Enterococcus, Staphylococcus aureus, Pseudomonas, and E.coli. In this study we did three different types of experiments for showing antibacterial activity of Neem leaf extract.

Agar well diffusion methods were used for testing of antimicrobial activity of neem extract. Except the control well, the significant zone of inhibition around the wells was seen. In agar well diffusion test, the zones of inhibition showed significant difference between the zone diameters of all four microorganisms tested. In this method also Staphylococcus aureus and enterococcus showed maximum zone of inhibition.

The second experiment was done by using Blood and MacConkey agar culture plates with neem extract as prepared above. The two sets of culture plates i.e. without and with neem extract showed the clear difference. The plates with neem extract showed significantly reduced growth or no growth as in case of Staphylococcus aureus and Enterococcus compared to plates without neem. Neem leaf extract was effective against all four microorganisms and showed maximum antimicrobial activity against Enterococcus > Staphylococcus $>$ Pseudomonas $>$ E. coli. (Table: $1,2 \& 3$ ). Inhibition of growth was maximum as the concentration of the neem extract in agar media increased from $2 \mathrm{ml}$ to $6 \mathrm{ml}$. Maximum growth inhibition was shown by $S$. aureus and Enterococcus.

\section{Tables for Neem Paper}

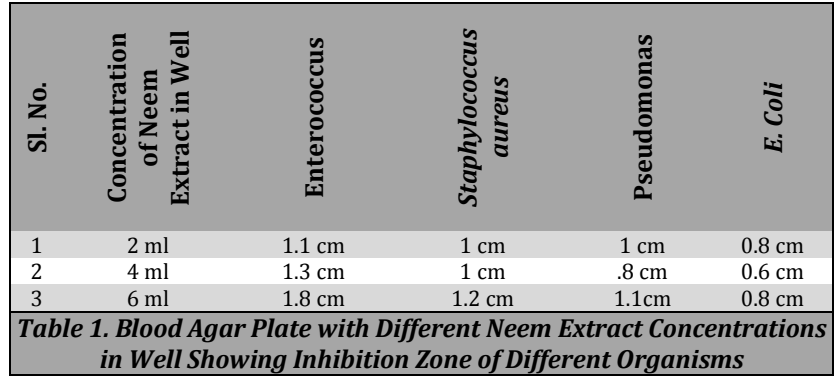

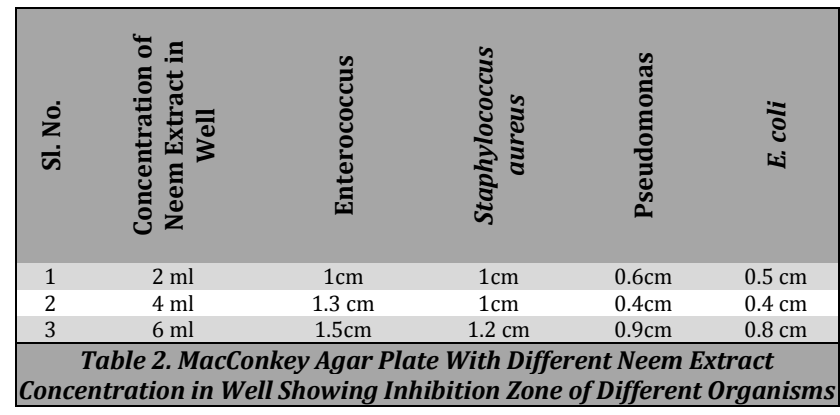

\begin{tabular}{|ccc|}
\hline Sl. No. & Organism & Inhibition $\%$ \\
1 & Enterococcus & $50 \%$ \\
2 & Staphylococcus aureus & $39 \%$ \\
3 & Pseudomonas & $21 \%$ \\
4 & E.coli & $19 \%$ \\
\hline Table 3. Antimicrobial Activity against Various Microorganisms \\
\hline
\end{tabular}

In third method also the inoculums with Staphylococcus aureus and Enterococcus showed no turbidity and no growth on blood agar plates. Significantly reduced growth was seen in case of E. coli and Pseudomonas.

\section{DISCUSSION}

Neem tree is found to be the most important medicinal plant. Its various parts like leaves, stem, root, and its extracts exhibit antibacterial, antifungal, antiviral, anti-inflammatory properties. ${ }^{11,14,15}$ Azadirachta indica leaves having bioactive compounds with antimicrobial effects are useful in primary health care. ${ }^{16}$ It is used as a medicinal plant as it can inhibit the growth of many pathogens that was proved by Rajasekaran. ${ }^{17}$

In the current study, we tested medicinal plant $A$. Indica (Neem), for its antimicrobial activity against target pathogens Enterococcus, Staphylococcus aureus, Pseudomonas, and E.coli. These microorganisms were found to be associated with different types of infections like dental caries, preoperative infections, inflammation, nosocomial infections etc. 8,10 Neem leaf extracts showed antibacterial activity against all the target pathogens used. ${ }^{18}$

The testing methods of neem extract used in this study was very much similar to other studies also. ${ }^{19,20}$ The two sets of culture plates i.e. without and with neem extract as prepared above, showed the clear difference. The plate with neem extract showed significantly reduced growth compared to plate without neem. Maximum inhibition of growth occurred as the concentration of the neem leaf extract had shown maximum antibacterial activity against enterococcus and neem extract in agar media increased from $2 \mathrm{ml}$ to $6 \mathrm{ml}$. Neem leaf extract was effective against all four microorganisms. This was very similar to other studies done by Dhanya Kumar, Bohora, Prashant et al.21,22,23 In our study the neem leaf extract was effective against $S$. aureus and Enterococcus at low concentration and also effective for Pseudomonas and E.coli but at higher concentration. The study by Dhanya Kumar et al. also showed the same pattern of results where increased concentration was effective on E. Faecalis. ${ }^{21}$ This experiment proved the antimicrobial properties of neem leaf extract.9,

In agar well diffusion test, the zones of inhibition showed the significant difference between the zone diameters of all four microorganisms tested. In this method also S. aureus and Enterococcus showed maximum zones of inhibition. ${ }^{20}$ Neem 
leaf extracts proved to have therapeutic utilization, for industrially useful product preparations e.g., various types of surface disinfectants, as endodontic irrigating fluid ${ }^{24}$ and as ingredients for preparing floor cleaners. ${ }^{12}$ Seeds and fruit extracts have also exhibited antibacterial activity at higher concentration. Neem bark extract (NBE) at the concentration of $100 \mu \mathrm{g} / \mathrm{ml}$ significantly blocked the entry of HSV - 1 into cells. ${ }^{25}$ After so many researches it's time to now use old medicinal knowledge of neem for better economic and therapeutic utilization that can be done by using modern approaches of drug development.

Traditionally, neem is used by Indian rural population for its medicinal properties since ancient times. Neem has a long history of use approximately 6000 years BP (Vedic period of India). In Ayurveda medicine, bark and leaves of the neem tree were used to treat skin diseases, flowers were used as stomachic tonic and fruits as a purgative and emollient The different types of organic compounds have been taken from different parts of the tree and are widely used as medicines and pesticides. A biologically active, volatile organic sulphur compound is obtained by crushing of fresh seeds of the plant.

The chief constituent din - propyl - disulphide has been found by 25 volatile compounds. Azadirachta indica seed is a most active antifeedant. The barks of root and stem have tonic, astringent, anti-periodic and other medicinal properties. The leaves, fruits and barks are indicated in the treatment of diseases and infections. For the treatment of fever, nausea, vomiting and skin diseases bark of the neem is traditionally used. The root bark is more effective than stem bark and young fruit in this case. The neem leaves are famous and used as an old remedy for skin diseases. For the treatment of intestinal worms, fresh juice of the leaf along with salt is used and along with honey for jaundice and skin diseases. The leaves are used in variety of forms (ointment, liniment, and poultice) as external applications for skin diseases. A fresh leaf decoction is used as an anti-septic. Bruises, sprains and swollen glands may be treated by a hot infusion of leaves. The fruits of neem trees are used as emollient and purgative for the control of intestinal worms, piles and urinary tract infections. The neem seed oil is a very important commercial medicinal product. It is an anti-septic and effective in treating skin diseases, sprains, ulcers, and rheumatism. The neem seed oil is also used in medical soaps due to its anti-septic property. This soap is very effective for cleaning wounds or sores and similar to dose of carbolic soap. ${ }^{12,25}$ Unlike neem seed oil, neem leaves have a pleasant odour. An extract from neem leaves can be prepared as an alcoholic tincture or as tea. It can be used in anti-ageing nourishing formulas, mouthwashes, face washes, shower gels, face mask, skin toners etc. Keeping all these properties in view, the experimental results are very encouraging to use the leaf extract of the neem tree as an anti- microbial product for general use of disinfection for the common pathogens.

\section{CONCLUSIONS}

Neem is commonly considered as medicinal tree in India. Its products are extensively used in Ayurveda and Unani medicines because of its antimicrobial properties. In olden times it was used as household remedy against various diseases. Now trends and awareness for using neem plant products as medicine and disinfectants are increasing. In this study alcoholic leaf extract of $A$. Indica, exhibits antimicrobial effects against the target pathogens Enterococcus, Staphylococcus aureus, Pseudomonas, and E.coli. It is a simple and inexpensive method for the better sanitization with no toxic effects.

\section{Work Attributed To}

Era's Lucknow Medical College and Hospital Lucknow, Era University, Lucknow, Uttar Pradesh, India

\section{Author's Contribution}

MAK - Concept, coordination, design of the study and interpreted the results, SY - Statistically analysed and interpreted; reviewed the literature and manuscript preparation; SA - statistically analysed and interpreted, preparation of manuscript and technical revision of the manuscript.

Data sharing statement provided by the authors is available with the full text of this article at jemds.com.

Financial or other competing interests: None

Disclosure forms provided by the authors are available with the full text of this article at jemds.com.

The authors take this opportunity to thank the management and administration of Era's Lucknow Medical College and Hospital Lucknow, Era University, Lucknow, Uttar Pradesh, India for the support provided to complete this project.

\section{REFERENCES}

[1] Chopra RN, Nayer SL, Chopra IC. Glossary of Indian medicinal plants. New Delhi: Council of Scientific and Industrial Research 1956.

[2] Chopra RN. Chopra's indigenous drugs of India. $2^{\text {nd }}$ edn. Calcutta: U.N. Dhur and Sons 1958.

[3] Schmutterer $\mathrm{H}$. The neem tree: source of unique natural products for integrated pest management, medicine, industry and other purposes. Germany: VCH Weinheim 1995.

[4] Chatterjee A, Pakrashi SC. The treatise on Indian medicinal plants. New Delhi: Publications and Information Directorate 1994.

[5] Anonymous. Doctors find neem good for skin diseases. New Delhi: Evening News 1985.

[6] Baswa M, Rath CC, Dash SK, et al. Antibacterial activity of Karanj (Pongamia pinnata) and neem (Azadirachta indica) seed oil: a preliminary report. Microbios 2001;105(412):183-9.

[7] Rao AR, Sukumar S, Paramasivam TV, et al. Study of antiviral activity of tender leaves of Margosa tree (Melia azadericta) on vaccinia and variola virus: a preliminary report. Indian J Med Res 1969;57(3):495-502.

[8] Tidjani MA, Dupont C, Wepierre J. Anti-inflammatory activity of Azadirachta indica. Planta Med Phytother 1989;23:259-66.

[9] Hoque MDM, Bari ML, Inatsu Y, et al. Antibacterial activity of guava (Psidium guajava L.) and neem (Azadirachtaindica A. Juss.) extracts against foodborne pathogens and spoilage bacteria. Foodborne Pathog Dis 2007;4(4):481-8. 
[10] Nayak A, Nayak RN, Soumya B, et al. Evaluation of antibacterial and anticandidial efficacy of aqueous and alcoholic extract of neem (Azadirachta indica): an in vitro study. Int J Res Ayurveda Pharm 2011;2(1):230-5.

[11] Biswas K, Chattopadhyay I, Ranajit K, et al. Biological activities and medicinalproperties of neem (Azadirachta indica). Current Science 2002;82(11):1336-45.

[12] Panda S, Kar PK, Martha SK. A review on natural floor cleaner and insect repellant. European Journal of Pharmaceutical and Medical Research 2018;5(4):273-5.

[13] https://www.gardeningknowhow.com/plant problems/pests/pesticides/neem-oil-uses.htm. Accessed on 19 - 12 - 2019).

[14] Subapriya R, Nagini S. Medicinal properties of neem leaves: a review. Curr Med Chem and Anticancer Agent 2005;5(2):149-56.

[15] Joshi B, Sah GP, Basnet BB, et al. Phytochemical extraction and antimicrobial properties of different medicinal plants: Ocimum Sanctum (Tulsi), Eugenia caryophyllata (clove), Achytanthes Bidentata (Datiwan) and AzadirachtaIndica (Neem). J Microbiol Antimicrob 2011;3(2):1-7.

[16] Koona S, Budida S. Antimicrobial potential of the extracts of the leave of Azadirachtaindica Linn. Nat Sci Biol 2011;3(1):65-9.

[17] Yerima MB, Jodi SM, Oyinbo K, et al. Effect of neem extracts (Azadirachtaindica) on bacteria isolated from adult mouth. Nigerian Journal of Basic and Applied Sciences 2012;20(1):64-7.

[18] Chandrasekaran R, Meignanam E, Vijayakumar V, et al. Investigations on antibacterial activity of leaf extracts of
Azadirachta indica A. Juss (Meliaceae): a traditional medicinal plant of India. Ethnobot Leaflets 2008;2008(1).

[19] Ghonmode WN, Balsaraf OD, Tambe VH, et al. Comparison of the antibacterial efficiency of neem leaf extracts, grape seed extracts and 3\% sodium hypochlorite against E. feacalis-an in vitro study. J Int Oral Health 2013;5(6):616.

[20] Mustafa M. Antibacterial efficacy of neem (Azadirachta indica) extract against enterococcus faecalis: an in vitro study. J Contemp Dent Pract 2016;17(10):791-4.

[21] Kumar D, Sidhu P. The antimicrobial activity of Azadirachta indica, Glycyrrhiza glabrat, Cinnamum zeylanicum, Syzygium aro-maticum, Acacia nilotica on Streptococcus mutans and Enterococcus faecalis-an in vitro study. Endodontology 2011;23(1):18-25.

[22] Prashant GM, Chandu GN, Murulikrishna KS, et al. The effect of mango and neem extract on four organisms causing dental caries: Streptococcus mutans, Streptococcus salivavius, Streptococcus mitis and Streptococcus sanguis: an in vitro study. Indian J Dent Res 2007;18(4):148-51.

[23] Bohora A, Hegde V, Kokate S. Comparison of antibacterial efficiency of neem leaf extract and $2 \%$ sodium hypochlorite against E. faecalis, C. Albicans and mixed culture. Endodontology 2010;22:10-3.

[24] Davis JM, Maki J, Bahcall JK. In vitro comparison of antimicrobial effects of various endodontic medicaments on enterococcus faecalis. J Endod 2007;33(5):567-9.

[25] Ahmad S, Maqbool A, Srivastava A, et al. Biological detail and therapeutic effect of azadirachta indica (neem tree) products-a review. J Evid Based Med Healthc 2019;6(22):1607-12. 